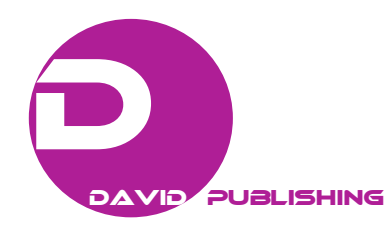

\title{
Effect of Porosity on the Wind Loads on a Hyperbolic Paraboloid Canopy Roof
}

\author{
Yasushi Uematsu $^{1}$, Yukari Miyamoto ${ }^{2}$ and Eri Gavansky ${ }^{1}$ \\ 1. Department of Architecture and Building Science, Graduate School of Engineering, Tohoku University, Sendai 980-8579, Japan \\ 2. Kume Sekkei Co. Ltd., Tokyo 135-8567, Japan
}

\begin{abstract}
A discussion is made of the wind force coefficients for designing the main wind force resisting systems of H.P. (Hyperbolic-Paraboid)-shaped porous canopy roofs on the basis of a wind tunnel experiment. Roof models with a number of small circular holes were made of nylon resin using laser lithography. The porosity was changed from 0 (solid) to 0.4 . Besides the porosity, the geometric parameters of the models were the rise to span ratio and slope of the roof. The overall aerodynamic forces and moments acting on a model were measured by a six-component force balance in a turbulent boundary layer. The results indicate that the porosity significantly reduces the wind loads. The design wind force coefficients for porous canopy roofs can be provided by those for solid roofs with the same configuration multiplied by a reduction factor. The proposed wind force coefficients are verified by a comparison of the load effect predicted by the proposed wind force coefficients with the maximum load effect obtained from dynamic analyses using the time history of wind force and moment coefficients. The axial forces induced in the columns supporting the roof are regarded as the load effect for discussing the design wind loads.
\end{abstract}

Key words: Canopy roof, hyperbolic paraboloid, porosity, wind tunnel experiment, main wind force resisting system, wind force coefficient, codification.

\section{Introduction}

In the Australasian and Middle Eastern countries, where it is dry and the sunlight is strong, the provision of sun protection has become a significant economic and health issue for humans, animals, and plants. For example, strong sunlight increases the incidence rate of skin cancer. Therefore, it is necessary to provide shade in public spaces where people gather, be it sports ground, school ground, shopping area or parking lot. H.P. (hyperbolic paraboloid) canopy roofs constructed of pre-tensioned membrane are widely used for this purpose. Fig. 1 shows examples of such roofs. Because these roofs are very lightweight structures that are vulnerable to wind actions, the wind resistance is one of the greatest concerns for structural engineers when designing these roofs. However, few specifications of

Corresponding author: Yasushi Uematsu, professor, research fields: architectural wind engineering (wind effects on buildings and structures, wind environment, wind power generation, etc.). E-mail: yu@archi.tohoku.ac.jp. design wind loads on H.P.-shaped canopy roofs are provided in codes and standards. Although the AS/NZ (Australia/New Zealand) Standard [1] provides the wind force coefficients for such roofs, the range of roof shape, or the rise to span ratio is rather limited.

A large database of knowledge exists for wind loads and wind-resistant design of enclosed buildings of various shapes, e.g., the studies of Dutt [2-4], Uematsu et al. [5], Fiouz and Karbaschi [6], Uematsu and Uchiyama [7], and Shen and Yang [8]. In contrast, only a few studies have been made of the wind loading on canopy roofs, which may be due to difficulties in model making and wind pressure measurement [9]. Recently, Uematsu et al. [10] proposed the wind force coefficients for designing the main wind force resisting systems of H.P.-shaped canopy roofs for a wider range of rise to span ratio, based on a wind tunnel experiment. However, the subject of the study was limited to solid roof with no porosity.

Shade cloth fabrics are often used for H.P.-shaped 


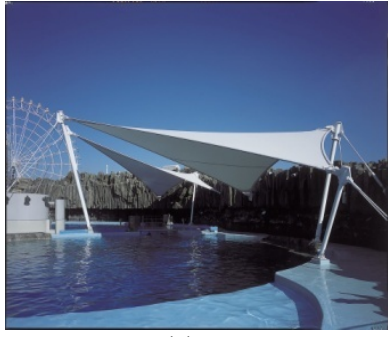

(a)

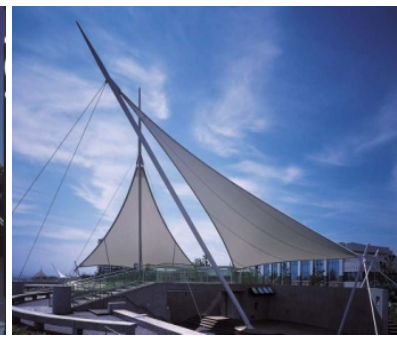

(b)
Fig. 1 H.P.-shaped canopy roofs constructed of pre-tensioned membrane (provided by Taiyo Kogyo Corporation): (a) with no roof slope; (b) with roof slope.

canopy roofs to provide shade. It is expected that the porosity of the fabrics reduces the net wind forces, or the pressure difference between the top and bottom surfaces. However, there is little information on the wind loading and structural response of suspended porous shade structures. Donnan et al. [11] reported the results of a wind tunnel experiment and structural analyses of a greenhouse structure constructed of shade cloth fabrics supported on cables. Letchford et al. [12] measured the mean lift and drag forces on a range of canopy roof forms with varying porosities. They used gable, hip and mono-sloped roof models made of thin perforated metal plates for three pitch angles, $7^{\circ}, 15^{\circ}$ and $27^{\circ}$, for porosity range from 0 (solid) to 0.23 . With a similar technique, Uematsu et al. [13] measured the overall wind force and moment coefficients on gable, troughed and mono-sloped roof models with roof pitches from $0^{\circ}$ to $20^{\circ}$ for a porosity range from 0 to 0.4 . Based on the results, they proposed the design wind force coefficients for each of the three roof geometries as a function of the pitch angle and porosity of the roof. To the authors' best knowledge, no study has been made of the wind loads on H.P.-shaped porous canopy roofs.

The present paper investigates the effect of porosity on the wind loads on H.P.-shaped porous canopy roofs on the basis of a wind tunnel experiment. Focus is on the main wind force resisting systems: cladding load is outside the scope of the present paper. A similar procedure that Uematsu et al. [13] used for planar canopy roof models is employed. The design wind force coefficients are provided as a function of the rise to span ratio, slope and porosity of the roof for three wind directions parallel to the diagonal lines of the roof.

\section{Experimental Arrangement and Procedures}

\subsection{Wind Tunnel Model}

Three models with different rise to span (or sag to span) ratios, as shown in Fig. 2, were tested. The model shape was the same as that Uematsu et al. [10] had used for solid roofs. Fig. 3 shows the notation and coordinate system used in the present paper. The roof

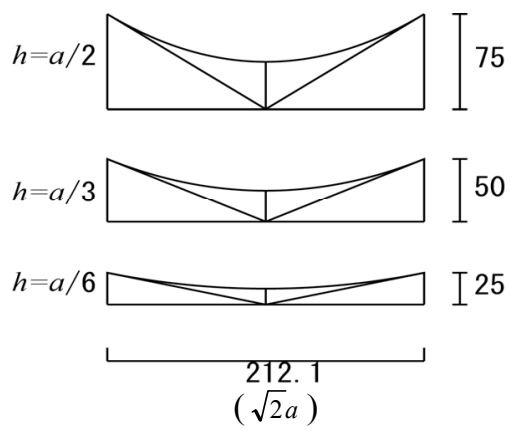

Fig. 2 Three roof shapes tested (unit: $\mathbf{m m}$ ).

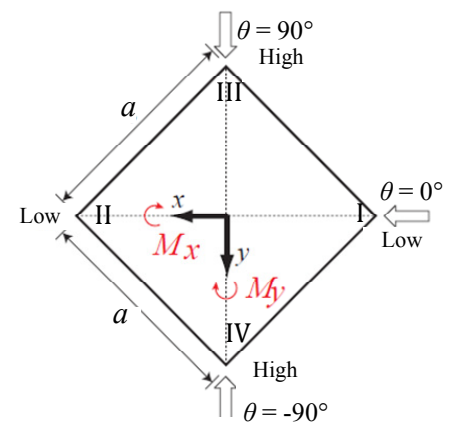

(a)

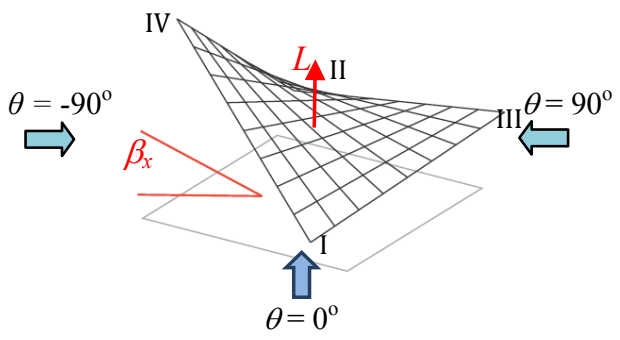

(b)

Fig. 3 Notation and coordinate system: (a) coordinate system; (b) definition of roof slope. 
corners are labelled "I" to "IV". The roof slope $\beta_{x}$, obtained by rotating the roof about the $x$-axis, was changed from $0^{\circ}$ to $40^{\circ}$ (Fig. 3b). The mean roof height $H$ was fixed to $80 \mathrm{~mm}$ regardless of $\beta_{x}$.

Fig. 4 shows a model with $h / a=1 / 2$, which was used for the wind tunnel experiment. The geometric scale $\lambda_{L}$ of the models was assumed 1/100. The models were made of nylon resin using laser lithography: the thickness was $1 \mathrm{~mm}$. The porosity was provided to the models by making a number of small circular holes. Uematsu et al. [13] measured the pressure loss coefficients $K$ for commonly used shade cloth fabrics and many thin perforated plates. They found that the value of $K$ for the shade cloth fabrics was in a range from approximately 9 to 45 . Furthermore, they derived the following empirical formula for the relationship between $K$ and porosity $p$, based on the results for perforated plates:

$$
K=0.52 p^{-2.6}
$$

Using this equation, we obtain the values of $p$ equal to 0.18 and 0.33 for $K=45$ and 9 , respectively. Therefore, we used two models with $p=0.2$ and 0.4 in the present study, which roughly cover the range of $K$ for practical shade cloth fabrics. A solid model was also tested for the purpose of comparison. The diameter $d$ of circular holes was $1 \mathrm{~mm}$ for both models, while the spacing $s$ was $2 \mathrm{~mm}$ for $p=0.2$ and $1.4 \mathrm{~mm}$ for $p=0.4$. The circular holes were drilled in the vertical direction, not in the normal direction of roof surface. The angle $\phi$ of the hole with respect to the normal direction depends on the $h / a$ ratio as well as on the location of the hole. The largest value of $\phi$ is approximately $13^{\circ}$ for $h / a=1 / 6,25^{\circ}$ for $h / a=1 / 3$ and $35^{\circ}$ for $h / a=1 / 2$, which is observed near the roof corners. In order to investigate the effect of $\phi$ on the pressure loss coefficient $K$, two perforated plates with different $\phi$ values, as shown in Fig. 5, were tested in a small wind tunnel [13]. Fig. 6 shows the results, in which $K$ is plotted against wind velocity $U$. It is found that the value of $K$ is little affected by $U$. In the case of $p=0.2$, the value of $K$ seems almost independent of $\phi$.
On the other hand, it is slightly dependent on $\phi$ in the case of $p=0.4$. Note that $\phi=35^{\circ}$ is the largest value of $\phi$ among all models and locations. Furthermore, only corner areas have such larger values. Therefore, it is thought that the overall aerodynamic forces and moments acting on the roof model are not affected by the inclination of holes significantly.

\subsection{Measurements of Aerodynamic Forces and Moments}

The experiments were carried out in a turbulent boundary layer with a power law exponent of $\alpha=0.21$ for the mean velocity profile. The lift $L$, positive upward, and the aerodynamic moments $M_{x}$ and $M_{y}$ about the $x$ and $y$ axes were measured by a six-component force balance (SSKLBW60-1). The lift coefficient $C_{L}$ and the aerodynamic moment coefficients $C_{M_{x}}$ and $C_{M_{y}}$ are defined as follows:

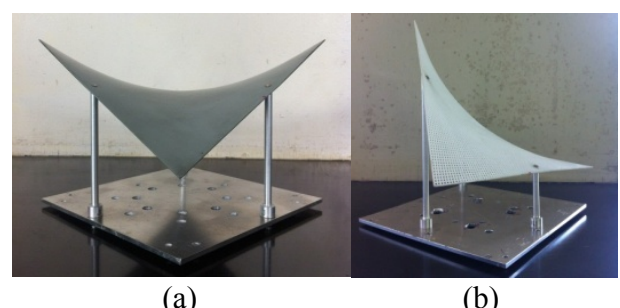

Fig. 4 Wind tunnel model $(h / a=1 / 2)$ : (a) $\beta_{x}=0^{\circ}$; (b) $\boldsymbol{\beta}_{x}=30^{\circ}$.

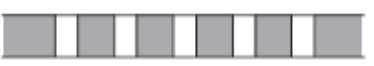

(a)

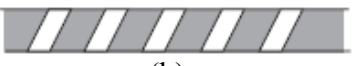

(b)
Fig. 5 Section of the perforated plates: (a) normal holes; (b) inclined holes.

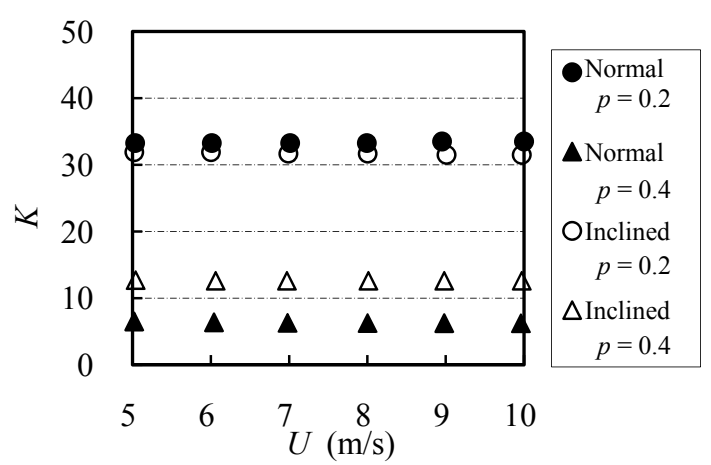

Fig. 6 Pressure loss coefficients $K$ for the perforated plates. 


$$
\begin{aligned}
C_{L} & =\frac{L}{q_{H} S} \\
C_{M_{x}} & =\frac{M_{x}}{q_{H} S a^{\prime}} \\
C_{M_{y}} & =\frac{M_{y}}{q_{H} S a^{\prime}}
\end{aligned}
$$

where, $q_{H}=$ time-averaged velocity pressure of the flow at the mean roof height $H(=80 \mathrm{~mm}) ; S=$ projected plan area of the roof $\left(=a^{2}\right) ; a^{\prime}=(\sqrt{2} / 3) a$, which is used as the reference length of the model and $a=150 \mathrm{~mm}$. The wind direction $\theta$ was changed from $0^{\circ}$ to $90^{\circ}$ for $\beta_{x}=0^{\circ}$ and from $-90^{\circ}$ to $90^{\circ}$ for $\beta_{x}>0^{\circ}$ (Fig. 3).

The measurements were carried out at a wind velocity of $U_{H} \approx 9 \mathrm{~m} / \mathrm{s}$ at the mean roof height $H$. The turbulence intensity $I_{u H}$ at this height was approximately 0.17 . The velocity scale $\lambda_{V}$ was assumed $1 / 3$, resulting in a time scale of $\lambda_{T}=1 / 33$. The outputs of the force balance were sampled

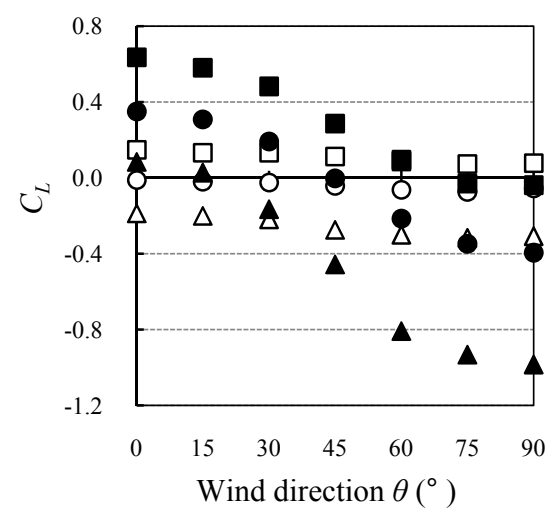

(a)

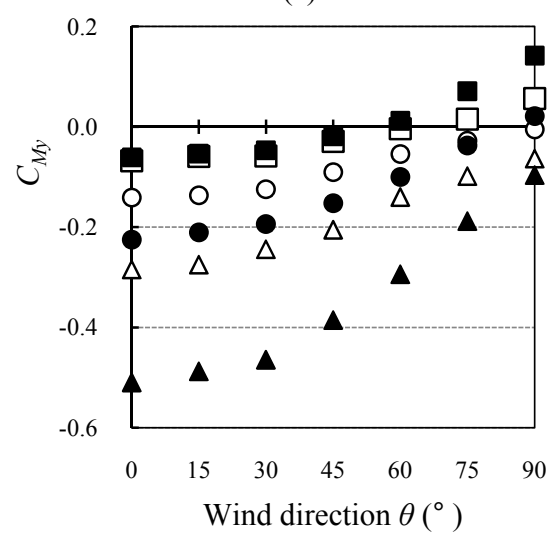

(c) simultaneously at a rate of $200 \mathrm{~Hz}$ for a period of $19 \mathrm{~s}$, which corresponds to $10 \mathrm{~min}$ in full scale. The measurements were repeated six times under the same condition. The statistics of the aerodynamic coefficients were evaluated by applying ensemble average to the results of these six consecutive runs. The wind forces on the three legs of $5 \mathrm{~mm}$ diameter (Fig. 4) supporting the roof were measured separately and were subtracted from the overall loads to produce load on the roof alone.

\section{Experimental Results}

3.1 Effect of Porosity on the Aerodynamic Forces and Moments

Fig. 7 shows the variation of $C_{L}, C_{M_{x}}$ and $C_{M_{v}}$ with wind direction $\theta$ for $h / a=1 / 2$ and $\beta_{x}=0^{\circ}$. In the figure, the mean and the maximum and minimum peak values of these aerodynamic coefficients are plotted against

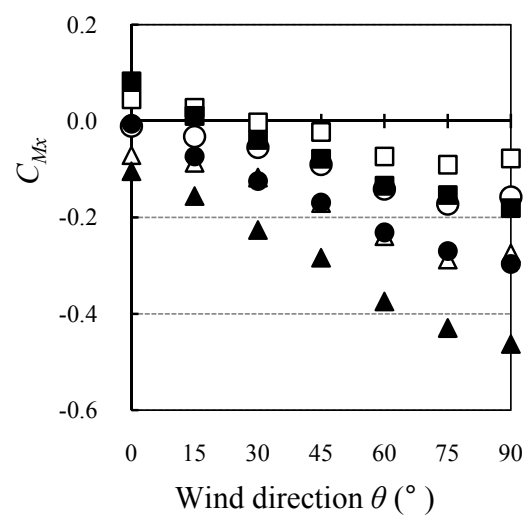

(b)

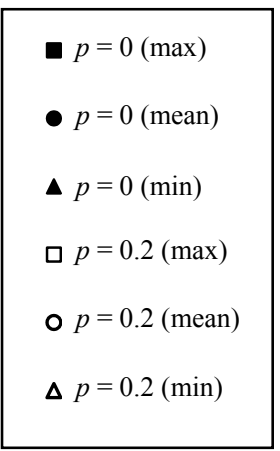

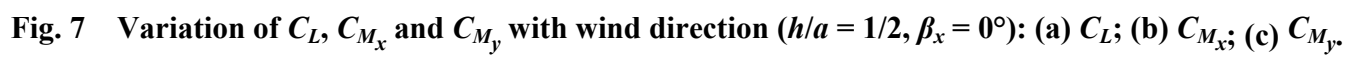


wind direction $\theta$. The general features of these coefficients may be summarized as follows. The lift coefficient $C_{L}$ becomes the maximum (upward) when $\theta$ $\approx 0^{\circ}$ and the minimum (downward) when $\theta \approx 90^{\circ}$. The negative peak value of $C_{M_{x}}$ becomes the maximum in magnitude when $\theta \approx 90^{\circ}$, while that of $C_{M_{y}}$ becomes the maximum when $\theta \approx 0^{\circ}$. The magnitude of $C_{M_{x}}$ for $\theta \approx 0^{\circ}$ and that of $C_{M_{y}}$ for $\theta \approx 90^{\circ}$ are relatively small. The variation of $C_{M_{x}}$ with $\theta$ is almost opposite to that of

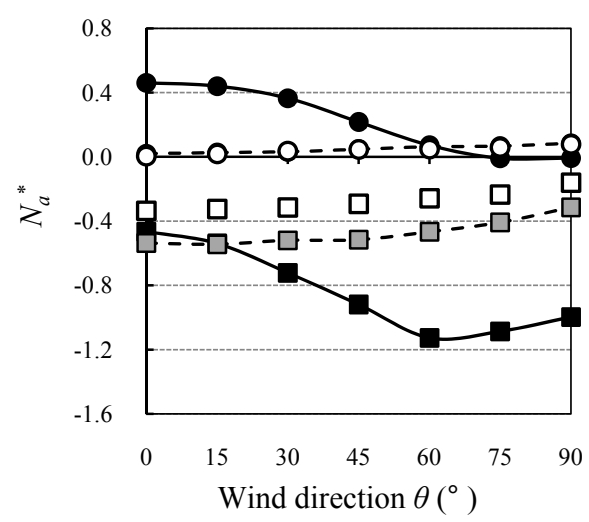

(a)

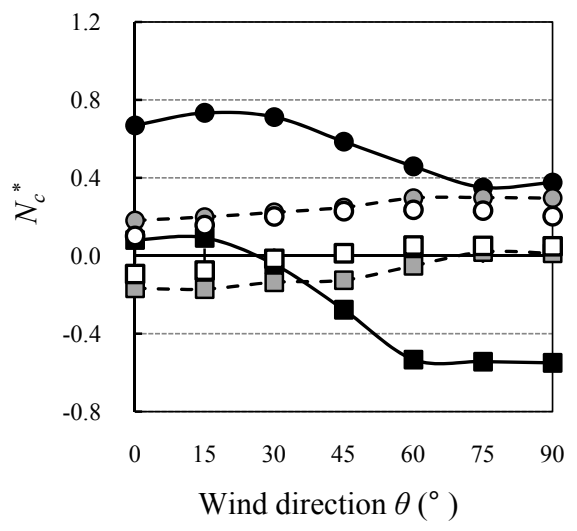

(c)

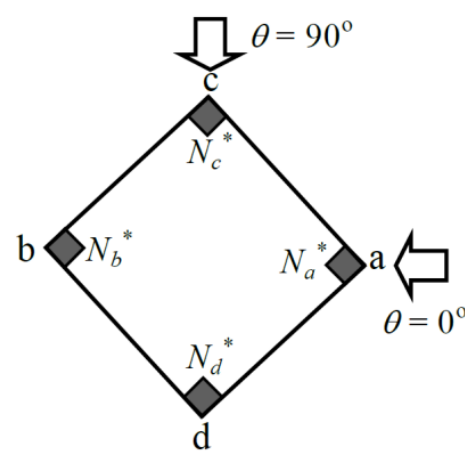

(e)
$C_{M_{y}}$. It is found that these coefficients significantly decrease in magnitude with an increase in porosity from 0 to 0.2 . The results for $p=0.4$, not shown here to save space, showed a further decrease in magnitude of these coefficients. However, the change was not so significant.

Fig. 8 shows the effect of porosity $p$ on the non-dimensional axial forces induced by wind forces in the corner columns (labeled "a" to "d") supporting the

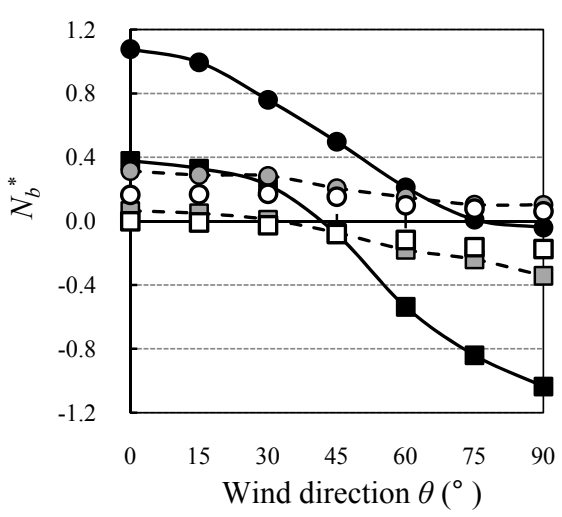

(b)

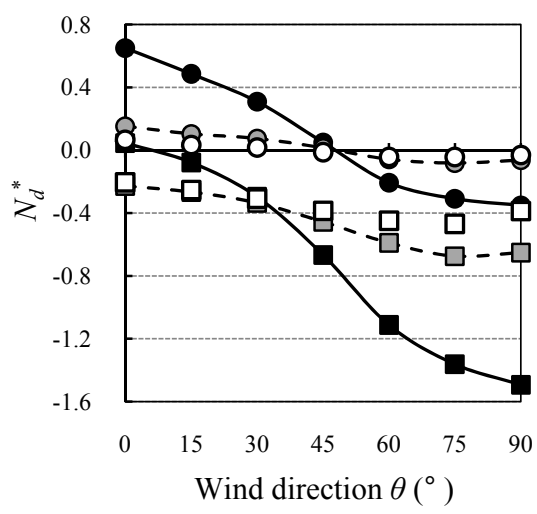

(d)

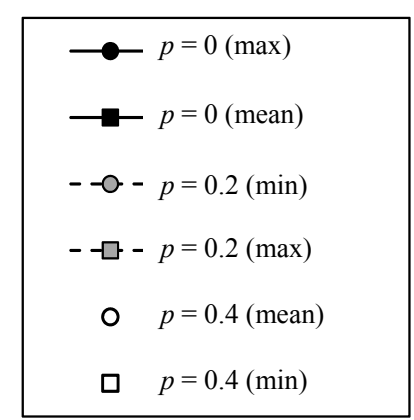

Fig. 8 Variation of non-dimensional column axial forces induced by wind forces with wind direction $\left(h / a=1 / 2, \beta_{x}=0^{\circ}\right)$ : (a) $N_{a}^{*}$; (b) $N_{b}^{*}$; (c) $N_{c}^{*}$; (d) $N_{d}^{*}$; (e) notation. 
roof for $h / a=1 / 2$ and $\beta_{x}=0^{\circ}$, in which the maximum (tension) and minimum (compression) peak values are plotted against wind direction $\theta$. The non-dimensional axial force $N_{i}^{*}(i=a-d)$ is defined as follows:

$$
N_{i}^{*}=\frac{N_{i}}{q_{H}(S / 4)}
$$

where, $N_{i}$ represents the axial force induced in the column by wind forces. It is clear that the porosity reduces the magnitude of axial forces, particularly in the cases where $\theta \approx 0^{\circ}$ and $90^{\circ}$.

\subsection{Wind Force Coefficients}

Uematsu et al. [10] proposed the wind force coefficients for designing the main wind force resisting systems of H.P.-shaped solid canopy roofs, which provide the equivalent static wind loads together with a gust effect factor $G_{f}$. The roof is divided into two areas, i.e., the windward and leeward halves, as shown in Fig. 9. The wind force coefficients $C_{N W}{ }^{*}$ and $C_{N L}{ }^{*}$ on these areas were provided as a function of $h / a$ for three wind directions (WD1 - WD3) parallel to the diagonal lines of the roof; WD3 corresponds to $\theta=-90^{\circ}$, which is considered only when $\beta_{x}>0^{\circ}$. Two load cases (A and B), generating the maximum tension and compression in the columns, were considered for each wind direction. The detail of the specification of the design wind force coefficients is presented in [10].

Then, the effect of porosity on the wind force coefficients was investigated. Figs. 10 and 11 show the results for WD1 and WD2, respectively, when $\beta_{x}=0^{\circ}$. As might be expected from the results of Figs. 7 and 8, the values of $C_{N W}{ }^{*}$ and $C_{N L}{ }^{*}$ generally decrease in magnitude with an increase in $p$. Hence, a reduction factor $R$, defined by the ratio of the $C_{N W}{ }^{*}$ or $C_{N L}{ }^{*}$ value for a porous canopy roof to that for the solid roof is introduced. The results for WD 1 and WD 2 are shown in Figs. 12 and 13, respectively. Note that the data are not plotted for the cases where the $C_{N W}{ }^{*}$ and $C_{N L}{ }^{*}$ values for solid roofs are very small in magnitude, because such cases provide unrealistic values of $R$. The results of Figs. 12 and 13 indicate that the value of $R$ generally decreases with an increase in $p$. The effect of $h / a$ on $R$ seems small. A similar feature was observed in our previous study [13], where we investigated the effect of porosity on the wind loads on planar canopy roofs of various shapes (gable, troughed and mono-sloped). Although the results for $R$ were scattered, we found that the envelope of the results could be given by the following equation:

$$
R=\mathrm{e}^{-2.0 p}
$$

That is, the wind force coefficients $C_{N W}{ }^{*}$ and $C_{N L}{ }^{*}$ for porous roofs can be provided by those for solid roofs multiplied by the reduction factor $R$. This relation is represented by the solid curves in Figs. 12 and 13. It is interesting to note that Eq. (6) can be applied to the H.P-shaped canopy roofs irrespective of $h / a$ ratio. The $C_{N W}{ }^{*}$ and $C_{N L}{ }^{*}$ values can be expressed as a function of $K$ by using Eqs. (1) and (6).

\subsection{Application of the Proposed Wind Force Coefficients}

The application of the proposed wind force coefficients provided by Uematsu et al. [10] and Eq. (6) in the present paper is investigated from the viewpoint of load effect. The maximum tension and compression

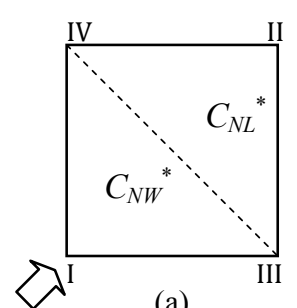

(a)

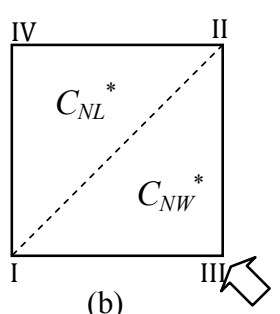

(b)

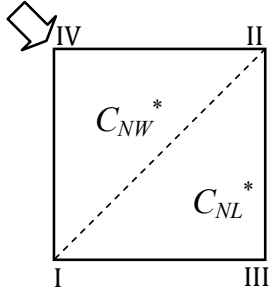

(c)

Fig. 9 Roof division and wind force coefficients: (a) WD1; (b) WD2; (c) WD3. 


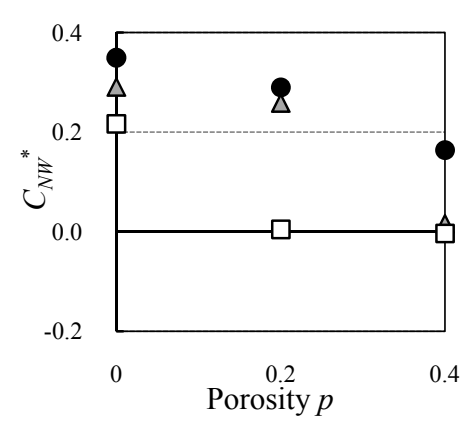

(a)

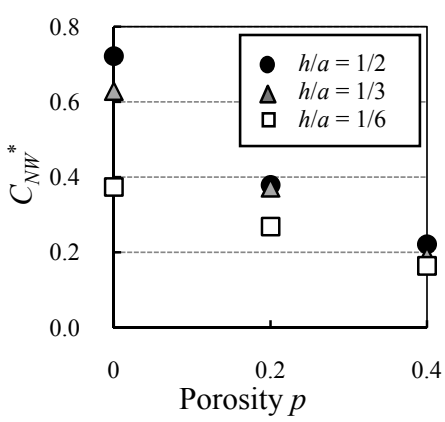

(c)

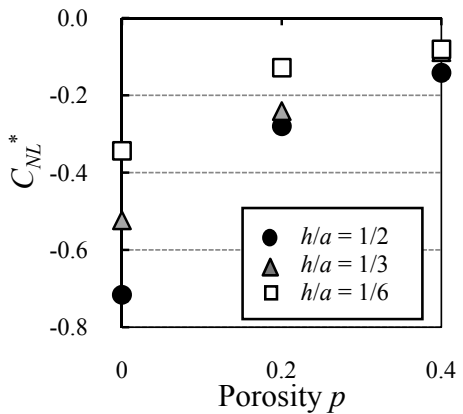

(b)

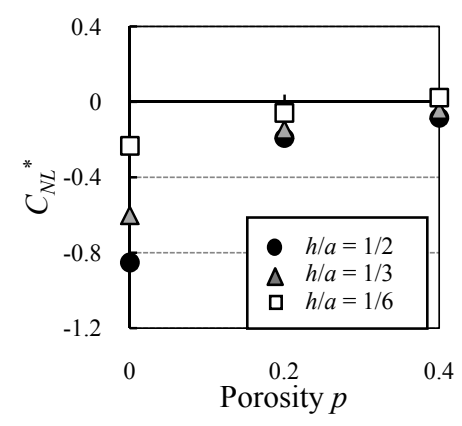

(d)

Fig. 10 Wind force coefficients for WD $1\left(\beta_{x}=0^{\circ}\right)$ : (a) $C_{N W}{ }^{*}\left(\operatorname{Load}\right.$ Case A); (b) $C_{N L}{ }^{*}\left(\operatorname{Load}\right.$ Case A); (c) $C_{N W}{ }^{*}(\operatorname{Load} \mathrm{Case} B)$; (d) $C_{N L}{ }^{*}($ Load Case B).

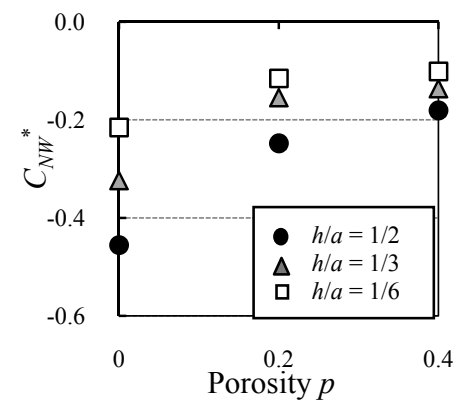

(a)

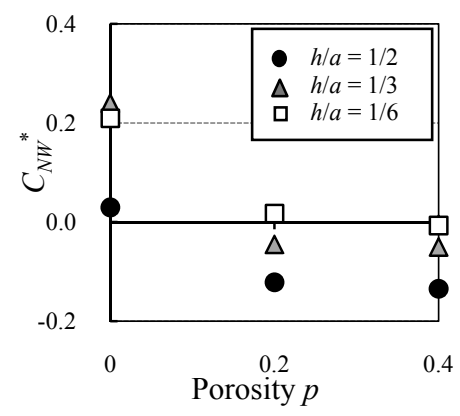

(c)

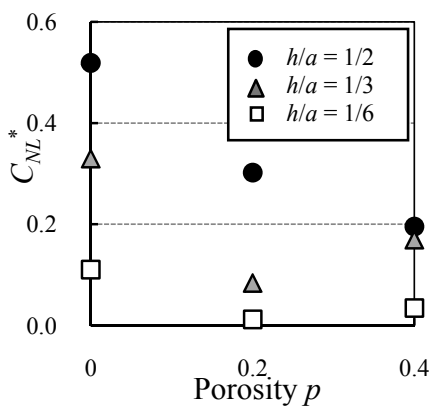

(b)

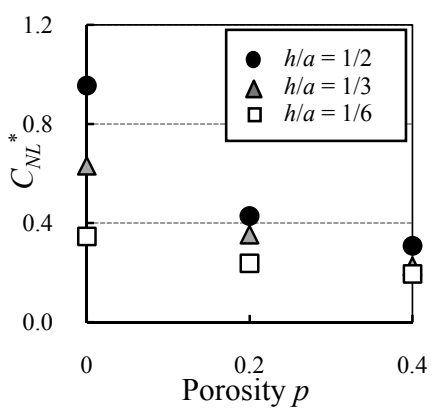

(d)

Fig. 11 Wind force coefficients for WD $2\left(\beta_{x}=0^{\circ}\right)$ : (a) $C_{N W}{ }^{*}\left(\operatorname{Load}\right.$ Case A); (b) $C_{N L}{ }^{*}\left(\operatorname{Load}\right.$ Case A); (c) $C_{N W}{ }^{*}(\operatorname{Load} \mathrm{Case} \mathrm{B})$; (d) $C_{N L}{ }^{*}($ Load Case B). 


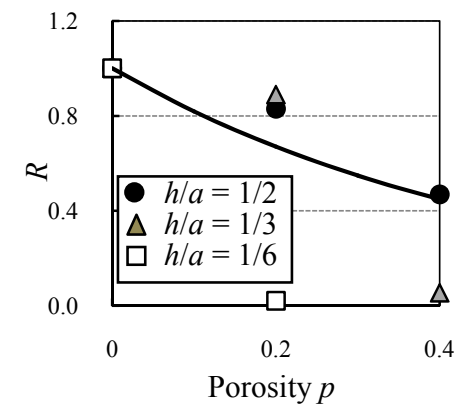

(a)

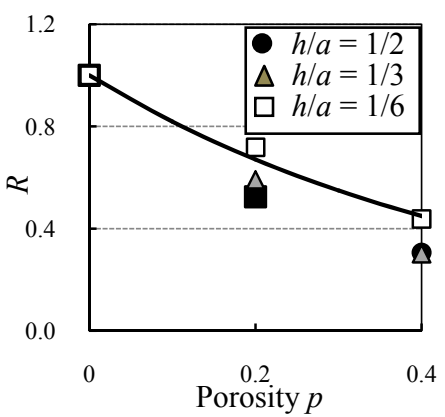

(c)

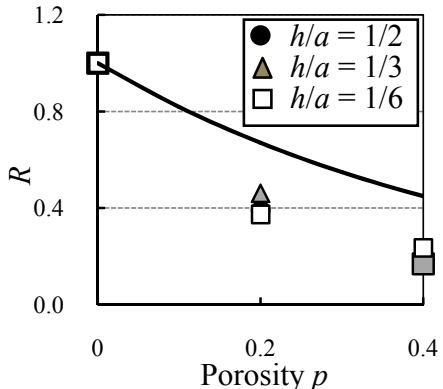

(b)

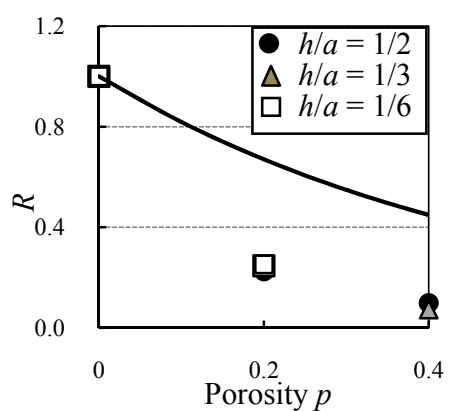

(d)

Fig. 12 Reduction factor $R$ for wind force coefficients $\left(\beta_{x}=0^{\circ}\right.$, WD1): (a) $C_{N W}{ }^{*}\left(\operatorname{Load}\right.$ Case A); (b) $C_{N L}{ }^{*}(\operatorname{Load}$ Case A); (c) $C_{N W}{ }^{*}\left(\operatorname{Load}\right.$ Case B); (d) $C_{N L}{ }^{*}(\operatorname{Load}$ Case B).

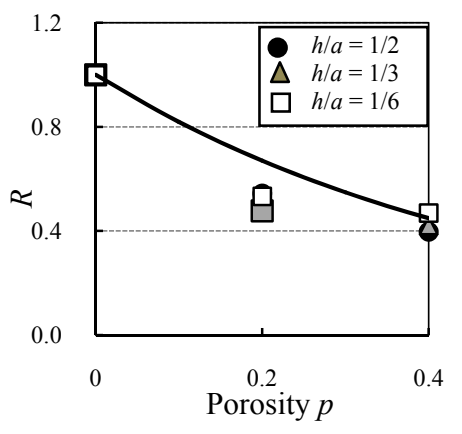

(a)

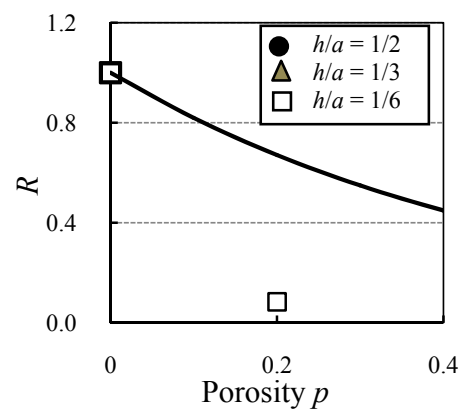

(c)

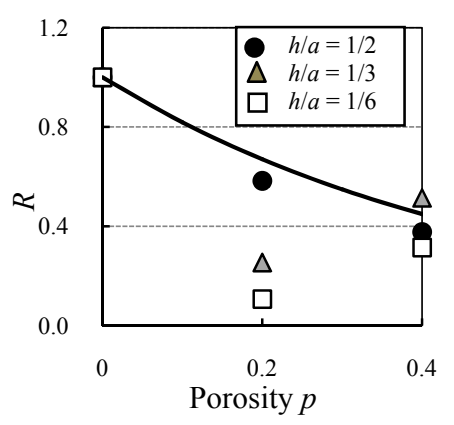

(b)

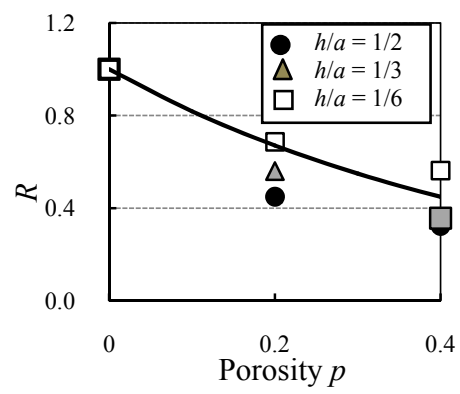

(d)

Fig. 13 Reduction factor $R$ for wind force coefficients $\left(\beta_{x}=0^{\circ}\right.$, WD2): (a) $C_{N W}{ }^{*}\left(\operatorname{Load}\right.$ Case A); (b) $C_{N L}{ }^{*}(\operatorname{Load}$ Case A); (c) $C_{N W}{ }^{*}\left(\operatorname{Load}\right.$ Case B); (d) $C_{N L}{ }^{*}(\operatorname{Load}$ Case B). 


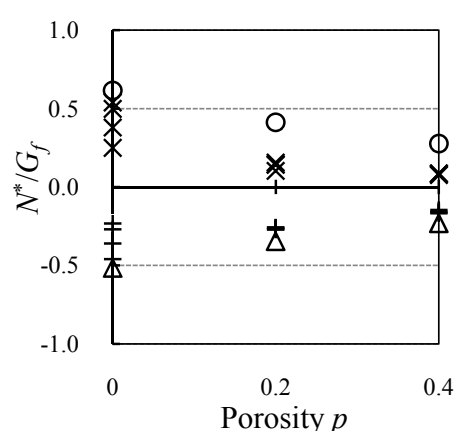

(a)

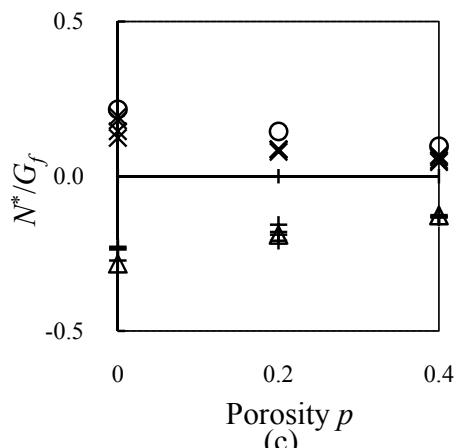

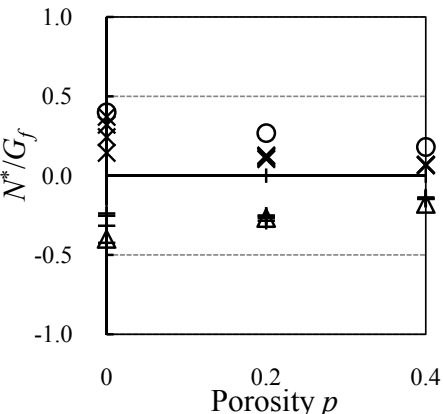

(b)

$$
\begin{aligned}
& \times N_{\max }^{*} \text { (time history) } \\
& +N_{\text {min }}^{*} \text { (time history) } \\
& \circ N_{\max }^{*} \text { (formula) } \\
& \Delta N_{\min }^{*} \text { (formula) }
\end{aligned}
$$

Fig. 14 Comparison between formula and time history analysis for column axial forces $\left(\beta_{x}=0^{\circ}\right.$, WD 1): (a) $h / a=1 / 2 ;(b) h / a$ $1 / 3 ;$ (c) $h / a=1 / 6$.

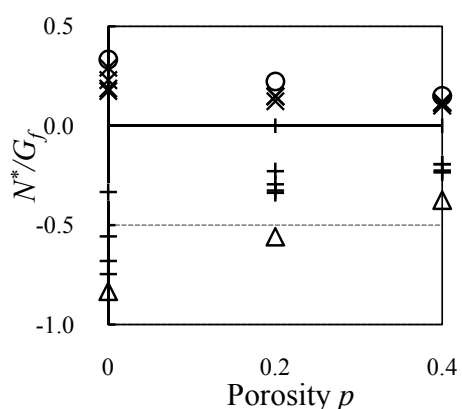

(a)

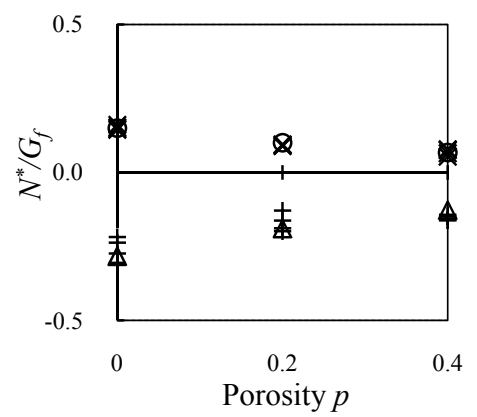

(c)

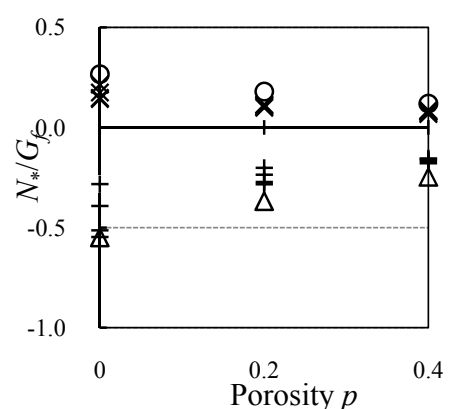

(b)

$$
\begin{aligned}
& \times N_{\text {max }}^{*} \text { (time history) } \\
& +N_{\text {min }}^{*} \text { (time history) } \\
& \circ N_{\text {max }}^{*} \text { (formula) } \\
& \Delta N_{\text {min }}^{*} \text { (formula) }
\end{aligned}
$$

Fig. 15 Comparison between formula and time history analysis for column axial forces $\left(\beta_{x}=0^{\circ}\right.$, WD2): (a) $h / a=1 / 2 ;(b) h / a$ $1 / 3$; (c) $h / a=1 / 6$. 


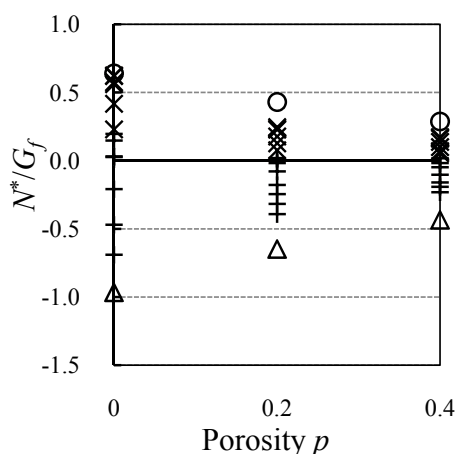

(a)

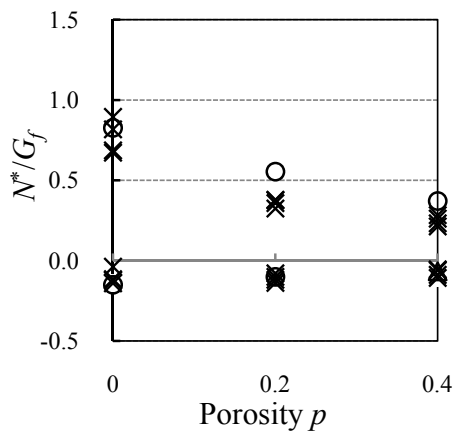

(c)

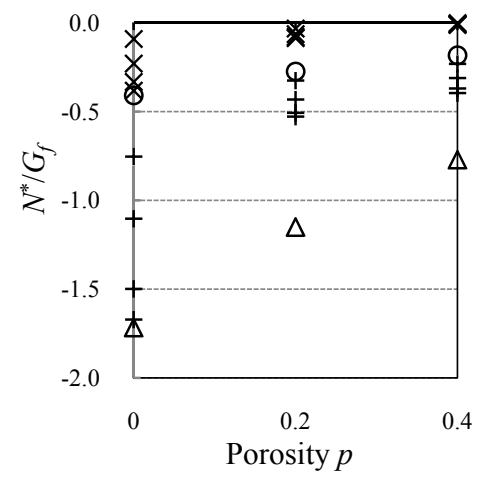

(b)

$\times N_{\max }^{*}$ (time history)
$+N_{\text {min }}^{*}$ (time history)
$\bigcirc N_{\max }^{*}$ (formula)
$\Delta N_{\min }^{*}$ (formula)

Fig. 16 Comparison between formula and time history analysis for column axial forces $\left(h / a=1 / 2, \beta_{x}=20^{\circ}\right)$ : (a) WD1; (b) WD2; (c) WD3.

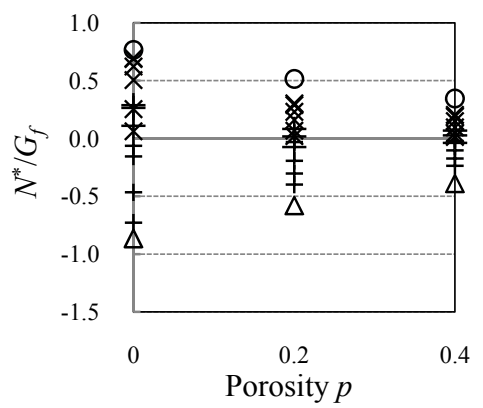

(a)

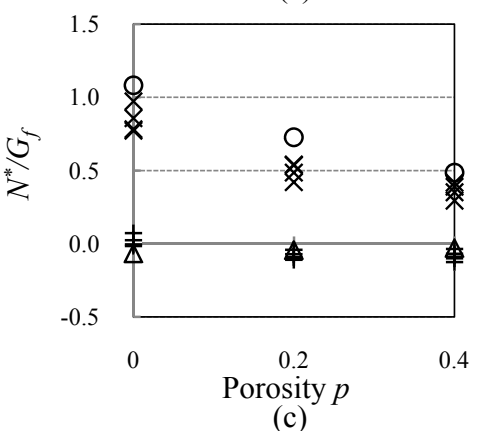

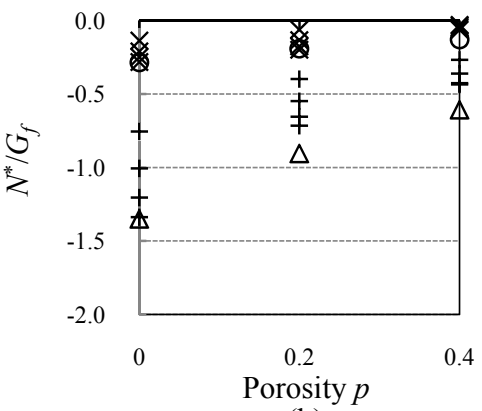

(b)

$$
\begin{aligned}
& \times N_{\text {max }}^{*} \text { (time history) } \\
& +N_{\text {min }}^{*} \text { (time history) } \\
& \circ N_{\text {max }}^{*} \text { (formula) } \\
& \Delta N_{\text {min }}^{*} \text { (formula) }
\end{aligned}
$$

Fig. 17 Comparison between formula and time history analysis for column axial forces $\left(h / a=1 / 2, \beta_{x}=40^{\circ}\right)$ : (a) WD1; (b) WD2; (c) WD3. 
induced in the corner columns supporting the roof are obtained from a time-history analysis and compared with the predicted values from the $C_{N W}{ }^{*}$ and $C_{N L}{ }^{*}$ values for solid roofs together with Eq. (6). The gust effect factor $G_{f}$ is assumed 2.0 according to our previous paper [10], in which the gust effect factor was discussed based on the load effect. Figs. 14 and 15 show the results for WD1 and WD2, respectively, when $\beta_{x}=0^{\circ}$. In the time history analysis, a range of wind direction is considered. That is, WD1 and WD2 represent wind direction ranges from $0^{\circ}$ to $45^{\circ}$ and from $45^{\circ}$ to $90^{\circ}$, respectively. Therefore, the results for several wind directions in each wind direction range (WD1 or WD2) are plotted in Figs. 14 and 15. The predicted values are nearly equal to or somewhat larger than those obtained from the time-history analyses for various wind directions.

Similar comparison was made for roofs with slopes $\left(\beta_{x}>0^{\circ}\right)$. Figs. 16 and 17 show the results for $\beta_{x}=20^{\circ}$ and $40^{\circ}$, respectively. Here, WD1 represents a wind direction range from $-45^{\circ}$ to $45^{\circ}$, because the measurements were carried out in a wind direction range from $-90^{\circ}$ to $90^{\circ}$ when $\beta_{x}>0^{\circ}$, while WD2 and WD3 represent wind direction ranges from $45^{\circ}$ to $90^{\circ}$ and from $-90^{\circ}$ to $-45^{\circ}$, respectively. It is found that the formulas provide appropriate estimation of the maximum load effects. The estimated values are nearly equal to or somewhat larger than those obtained from the time history analyses, as in the case of $\beta_{x}=0^{\circ}$ (Figs. 14 and 15).

These results suggest that the wind force coefficients proposed by Uematsu et al. [10] and the reduction factor $R$ defined in the present paper can appropriately evaluate the design wind loads on H.P.-shaped porous canopy roofs.

\section{Conclusions}

The wind force coefficients for designing the main wind force resisting systems of H.P.-shaped porous canopy roofs have been proposed on the basis of a wind tunnel experiment with rigid porous models. The overall aerodynamic forces and moments acting on the roof models with rise to span ratios of $h / a=1 / 2,1 / 3$ and $1 / 6$ were measured by a six-component force balance in a turbulent boundary layer. The roof slope $\beta_{x}$ obtained by raising one of the higher corners and lowering the other corner was changed from $0^{\circ}$ to $40^{\circ}$. The porosity of the model was changed from 0 (solid) to 0.4 , and the effect of porosity on the wind loads was investigated. For discussing the design wind loads, focus is on the axial forces induced in the columns as the load effect, assuming that the roof is rigid and supported by the four corner columns.

The results indicate that the porosity of the roof reduces the wind loads on the roofs significantly. The effect is represented by a reduction factor $R$. That is, the design wind force coefficients for porous roofs are given by the product of the wind force coefficients for solid roofs and the reduction factor. The wind force coefficients for solid roofs were proposed by Uematsu et al. [10] as a function of $h / a$ and $\beta_{x}$. The reduction factor is given by a simple exponential function of porosity $p$ in the present paper.

The validity of the proposed formulae was confirmed on the basis of a comparison between the maximum load effects obtained from the formulae with those computed from the time history analysis using the time history of the aerodynamic force and moment coefficients measured in the wind tunnel experiment.

In practical structures, the deformation and oscillation may affect the wind loads. Furthermore, the other roof supporting systems different from that considered in the present study may be used, e.g., "post and guy cable" system. The application of the wind force coefficients proposed in the present paper to such cases should be investigated. These are the subjects of future studies. A CFD (computational fluid dynamics) analysis is planned to investigate these subjects.

\section{References}

[1] Standards Australia. 2011. Australia/New Zealand Standard AS/NZ 1170.2. Standards Australia. 
[2] Dutt, A. J. 1985. "Wind Loading on a Pyramidal Roof Structure.” International Journal of Space Structures 1: 105-10.

[3] Dutt, A. J. 1986. "Wind Pressure Distribution on Multiple Hyperbolic Paraboloid Shell Roof Building." International Journal of Space Structures 2: 49-54.

[4] Dutt, A. J. 1988. "Wind Loading on a 'Saw Tooth' Multiple Hyperbolic Paraboloid Shell Roof." International Journal of Space Structures 3: 43-50.

[5] Uematsu, Y., Sone, T., Yamada, M., and Hongo, T. 2002. "Wind-Induced Dynamic Response and Its Load Estimation for Structural Frames of Single-Layer Latticed Domes with Long Span." Wind and Structures 5 (6): 543-62.

[6] Fiouz, A., and Karbaschi, M. E. 2012. "Effect of Wind Loading on Spherical Single Layer Space Truss Steel Domes." International Journal of the Physical Sciences 7 (16): 2493-505.

[7] Uematsu, Y., and Uchiyama, K. 1986. "Aeroelastic Behavior of an H.P.-Shaped Suspended Roof." In Proceedings of IASS (International Association for Shell and Spatial Structures) Symposium, 241-8.

[8] Shen, S., and Yang Q. 1999. "Wind-Induced Response
Analysis and Wind-Resistant Design of Hyperbolic Paraboloid Cable Net Structures." International Journal of Space Structures 14 (1): 57-65.

[9] Uematsu, Y., Iizumi, E., and Stathopoulos, T. 2007. "Wind Force Coefficients for Designing Free-Standing Canopy Roofs." Journal of Wind Engineering and Industrial Aerodynamics 95: 1486-510.

[10] Uematsu, Y., Miyamoto, Y., and Gavansky, E. 2014. "Wind Loading on a Hyperbolic Paraboloid Free Roof." Journal of Civil Engineering and Architecture 8 (10): 1233-42.

[11] Donnan, R. L., Walker G. R., and Jancauskas, E. D. 1987. "Design of a Low Cost Wind Resistant Shade Cloth Structure." Presented at the First National Structural Engineering Conference, Melbourne, Australia.

[12] Letchford, C. W., Row, A., Vitale, A., and Wolbers, J. 2000. "Mean Wind Loads on Porous Canopy Roofs." Journal of Wind Engineering and Industrial Aerodynamics 84: 197-213.

[13] Uematsu, Y., Sakurai, H., Miyamoto, Y., and Gavansky, E. 2013. "Wind Force Coefficients for Designing Porous Canopy Roofs." Journal of Civil Engineering and Architecture 7 (9): 1047-55. 